\title{
INFLUENCE OF DIFFERENT NITROGEN SOURCES ON GROWTH AND PATHOGENIC CAPABILITY OF Rhizoctonia solani CAUSING ROOT ROT OF FABA BEAN
}

\author{
Maha H. Mohamed ${ }^{\star}$ and Mostafa H.M. \\ Plant Pathology Dept., Fac. of Agric., Ain Shams Univ., P.O. Box 68, Hadayek Shobra 11241, \\ Cairo, Egypt
}

[129]

*Corresponding author: maha helmy83@agr.asu.edu.eg

Received 19 October, 2018

Accepted 7 December, 2018

\begin{abstract}
The effect of replacement different nitrogen sources (glucosamine sulfate, ammonium sulfate, aspartic acid, phenylalanine and peptone) instead of $\mathrm{NaNO}_{3}$ in Czapek's synthetic medium was studied on the growth of Rhizoctonia solani and its pathogenicity on faba bean germinated seeds. Ammonium sulfate exhibited faster growth and showed the same effect as the basal medium, while glucosamine sulfate showed the lower growth values compared with control. Glucosamine sulfate and ammonium sulfate showed significant reduction in number of infection cushions on germinated faba bean seeds which led to significant decrease of disease index in vitro. Results also, showed high correlations between disease index and both of diameters of hyphae and number of infection cushions, while very weak correlation coefficient was found between disease index and growth of $R$. solani. Under greenhouse conditions, glucosamine sulfate and peptone as sole nitrogen sources in sandy pots depressed the virulence of the fungus. The effect of different amounts of glucosamine sulfate was determined on fungal growth, infection cushions, disease index in vitro and polyphenol oxidase activity in vivo. Increasing amount of glucosamine sulfate showed significant reduction of fungal growth compared with sodium nitrate. All germinated seeds subjected to $R$. solani grown on different amounts of glucosamine sulfate, showed the lower number of infection cushions, disease index and polyphenol oxidase activity compared with sodium nitrate. Under greenhouse conditions, disease index significantly decreased when glucosamine sulfate was used as soil appli-
\end{abstract}

cation and showed better effect on fresh weights of shoot and root compared with control plants treated with sodium nitrate.

Keywords: Rhizoctonia solani, faba bean, Vicia faba, nitrogen sources, glucosamine sulfate, pathogenicity.

\section{INTRODUCTION}

Nitrogen is an essential element for the growth of all living organisms including fungi and soil microorganisms. Fungi possess the ability to use organic or inorganic nitrogen sources in nourishment medium (Marzluf, 1997). The form of nitrogen available to plant pathogenic fungi affects the fungal growth, sporulation, and pathogenicity genes. The ability of fungi to use various forms of nitrogen and its effect on hyphal morphology, growth and sporulation has been investigated. For instance, the colony and hyphal morphology of Verticillium albo-atrum were affected, and a reduction of the radial growth rate was recorded, when it was grown on medium containing glucosamine (White and Gadd, 1983).

Eight different nitrogen sources (ammonium nitrate, asparagine, glutamine, glycine, potassium nitrate, sodium nitrate, sodium nitrite and tryptophan) were tested on mycelial dry weight of eight Fusarium spp. isolated from agricultural soil in West Bengal, India. Organic nitrogen sources (except glutamine) were more effective to increase mycelial growth of all tested isolates than the inorganic nitrogen sources. Otherwise, sodium nitrate was the best source of inorganic nitrogen to increase growth of all Fusarium isolates tested (Islam, 2015). 
As well, among of different nitrogen sources including $\mathrm{KNO}_{3}, \mathrm{NaNO}_{3}$, peptone, tryptone, ammonium nitrate, and urea, Jabin and Nasreen (2016) evidenced that $\mathrm{KNO}_{3}$ was found to be the favorable for growth of Alternaria solani followed by $\mathrm{NaNO}_{3}$, peptone and tryptone, that they stimulated the growth, while urea exhibited the poorest growth.

On the other side, few of researchers reported that the nitrogen source is proposed to act as a regulatory switch to stimulate expression of pathogenicity related genes in plant pathogenic fungi. However, ammonia salts stimulated diseases caused by Rhizoctonia spp., Fusarium spp. and Sclerotium spp. on tomato, cotton, sugar beet, wheat and citrus, while the form of nitrate favored other pathogens such as Pythium causing root rots in corn and pea (Huber and Watson, 1974).

Mycelial growth of Phytophthora cinnamomi, the causal of root rot of avocado, was significantly increased by amendment broth media with nitrate nitrogen, while no significant effect was observed when media supplemented with urea or ammonium nitrogen compared with unamended broth media. Avocado seedlings treated with ammonium sulfate showed significant decrease of disease severity than when nitrate nitrogen or urea were used (Duvenhage et al 1992).

The aim of this study was to evaluate the effect of different nitrogen sources on growth and their amendment in inoculum substrate on pathogenic capability of Rhizoctonia solani on germinated seeds of faba bean.

\section{MATERIALS AND METHODS}

Rhizoctonia solani AG4-HGI (Mohamed et al 2015b) and faba bean seeds cv. Giza were used throughout this study.

1. Effect of different nitrogen sources on growth and pathogenicity in vitro

\subsection{On growth}

The effect of nitrogen sources on the growth of $R$. solani was carried out by growing a piece $5 \mathrm{~mm}$ in diam. of young hyphae on Petri dishes $(9 \mathrm{~cm})$ containing Czapek's medium consisting of $3 \mathrm{~g}$ $\mathrm{NaNO}_{3}, 1 \mathrm{~g} \mathrm{~K}_{2} \mathrm{HPO}_{4}, 0.5 \mathrm{~g} \mathrm{MgSO}_{4} .7 \mathrm{H}_{2} \mathrm{O}, 0.5 \mathrm{~g}$ $\mathrm{KCl}, 0.01 \mathrm{~g} \mathrm{FeSO}_{4}, 1 \mathrm{ml}$ of $\mathrm{ZnSO}_{4}, \mathrm{CuSO}_{4}, 30 \mathrm{~g}$ sucrose, $20 \mathrm{~g}$ agar and distilled water up to one liter. Sodium nitrate of the basal medium was substituted with equivalent units of nitrogen compounds of glucosamine sulfate, ammonium sulfate, aspartic acid, phenylalanine, and amount of pep- tone added was equal to the weight of sodium nitrate that present in Czapek's medium. Before sterilization, the $\mathrm{pH}$ of all media was adjusted to 7.0 with $0.1 \mathrm{~N} \mathrm{NaOH}$ or $\mathrm{HCl}$. Diameter of fungal colonies was recorded after $72 \mathrm{hr}$. Such growth average was measured in six replicates.

\subsection{Pathogenic capabilities}

To determine the effect of different nitrogen sources on the virulence of $R$. solani, sterilized faba bean germinated seeds were set on fungal growth plates with each nitrogen source, $18 \mathrm{hr}$ after that, five germinated seeds were taken for count of infection cushions as described below. Plates were incubated at $25 \pm 1^{\circ} \mathrm{C}$ for three days in the dark, and then disease index was determined according to increase grades 1-5 (Mohamed et al 2014). Six dishes (each contains 5 seeds) were used as replicates.

\section{Microscopic examination}

Eighteen hours after setting germinated faba bean seeds on fungal colonies, the lower surface of infected cotyledons (the site of infection) were stripped and stained with $0.1 \%$ trypan blue in $5 \%$ lactophenol then transferred to a glass slide for examination with a light microscope (Leica DM 2500). Five seeds of each treatment were taken for count of infection cushions and diameter of fungal hyphae on site of infection in 5 microscopic fields/seed (25 microscopic fields/treatment).

3. Effect of preparing fungal inoculum with different nitrogen sources on its pathogenicity

\subsection{Preparation of inoculum}

To evaluate the effect of different nitrogen sources on pathogenicity of $R$. solani under greenhouse conditions, sodium nitrate of Czapek's broth medium was replaced with equivalent amounts of nitrogen units of different nitrogen sources, peptone was added as $3 \mathrm{~g} / \mathrm{L}$ of water.

Sand used in this study was subject to $\mathrm{HCl}$ $(1 \mathrm{~N})$ in order to eliminate any carbonate salts, then washed several times in distilled water till $\mathrm{HCl}$ completely removed. Washed sand was left to dry then autoclaved, thereafter it was placed in $9 \mathrm{~cm}$ Petri dishes (120 g sand/dish). Each nitrogen source applied in Czapek's medium was added separately to the sand dishes ( $25 \mathrm{ml} / \mathrm{dish})$. Dishes were inoculated with active mycelia of $R$. solani, and incubated at $25 \pm 1{ }^{\circ} \mathrm{C}$ in the dark for 10 days. Dishes with fungal growth were used for infestation of sandy pots. 


\subsection{Infestation of sandy pots and cultivation of seeds}

Sterilized sand was distributed in plastic pots (10 $\mathrm{cm}$ in diameter), each pot contained approximately $430 \mathrm{~g}$ sand. Pots were infested with fungal inoculum growing on different nitrogen sources (one plate/pot). Infested pots were left for six days with follow up irrigation. Germinated faba bean sterilized seeds were sown in infested sand pots with $R$. solani as well as uninfested. Pots were irrigated when needed with sterilized tap water.

\subsection{Determination of disease index and plant growth characters}

Twenty days after sowing, number of emerged plants was calculated. Plants were taken and washed to release adhered sand for determination of disease index and plant growth parameters as stem length $(\mathrm{cm})$, number of leaves per plant, fresh shoot weight $(\mathrm{g})$, and fresh root weight $(\mathrm{g})$. These parameters were determined 28 days after sowing. Disease index of root rot was determined according to increase grades 1-9 (Mohamed et al 2015a).

\section{Effect of different amounts of glucosamine sulfate on fungal growth and disease index in vitro}

In other experiment, the effect of different amounts of glucosamine sulfate on fungal growth and disease index in vitro was studied. Such effect on growth and the virulence of $R$. solani was achieved by growing young hyphae on Petri dishes $(9 \mathrm{~cm})$ containing Czapek's medium. Sodium nitrate of the basal medium was substituted with half, equivalent and double weights of glucosamine sulfate $(5.89,11.78 \& 23.56 \mathrm{~g} / \mathrm{L}$, respectively) and the basal medium with optimum quantity of sodium nitrate $(3 \mathrm{~g} / \mathrm{L})$ was used as control. The $\mathrm{pH}$ of all media was adjusted to 7.0 before sterilization. Diameter of growth colonies (after $72 \mathrm{hr}$ ) and disease index ( 3 days after setting sterilized germinated faba bean seeds on the fungal growth media) were determined as described above.

\section{Effect of different amounts of glucosamine sulfate on polyphenol oxidase (PPO) activity}

Germinated seeds of each treatment were taken $72 \mathrm{hr}$ after inoculation and grinded in phosphate buffer solution (1:2, w:v - pH 6.0). Suspensions were centrifuged at $10000 \mathrm{rpm}$ for $10 \mathrm{~min}$ at $4^{\circ} \mathrm{C}$. Supernatant was taken for PPO activity determination by using catechol as substrate. The reaction mixture contained freshly prepared of $0.25 \mathrm{ml}$ of crude enzyme, $0.25 \mathrm{ml}$ of $50 \mathrm{mM}$ catechol and $1 \mathrm{ml}$ of $0.1 \mathrm{M}$ phosphate buffer, $\mathrm{pH}$ 7.0. The enzyme activity was determined by measuring the increase of optical density at $410 \mathrm{~nm}$ (Ünal, 2007). The absorbance was recorded after 15 minutes using ultraviolet-visible spectrophotometer, (Unico UV2100) USA. All determinations were carried out in three replicates.

6. Effect of different amounts of glucosamine sulfate on disease index and plant growth characters under greenhouse conditions

\subsection{Preparation of inoculum and infestation of sandy soil}

Procedure of preparation of $R$. solani inoculum and infestation of sandy pots, was conducted as mentioned above, except that fungal inocula were grown on basal Czapex's broth medium, they were add to sand dishes. Dishes were infested with actively $R$. solani growth, and incubated till it was colonized the substrate. Dishes with fungal growth were used for infestation of pots (dish/pot). Glucosamine sulfate at three weights were amended to sand soil as described below.

\subsection{Cultivation of seeds and determination of plant growth characters}

Germinated faba bean sterilized seeds were sown in sand pots infested with $R$. solani or not. Each pot received $30 \mathrm{ml}$ of three amounts of glucosamine sulfate $(5.89,11.78$, or $23.56 \mathrm{~g} / \mathrm{L}), 3 \mathrm{~g} / \mathrm{L}$ sodium nitrate or distilled water as control. Each treatment included infested and non infested pots (9 pots/applicate). Pots were irrigated daily with tap distilled water. After 20 days from sowing, number of emerged plants was calculated and after 28 days, plant growth characters (i.e. stem length, number of leaves per plant, fresh weights of shoot and root) were also determined.

\section{Statistical analysis}

Experimental data were statistically analyzed by analysis of variance (ANOVA) using The Statistical Analysis System (SAS) (Littell et al 1996). Standard deviation (SD) was calculated according to Ghahramani (2000). 


\section{RESULTS}

The effect of growing $\boldsymbol{R}$. solani in Czapek's medium amended with different nitrogen compounds on fungal growth and its pathogenicity on germinated faba bean seeds

Results in Fig. (1) indicate that ammonium sulfate as a sole source of nitrogen in Czapex's promoted maximal growth as compared with standard source, i.e. sodium nitrate. However, other tested sources of nitrogen clearly reduced values of mycelial growth than control, glucosamine sulfate caused the lowest category of growth.

The effect of nitrogen sources on pathogenicity was determined in vitro, glucosamine sulfate and ammonium sulfate showed significant reduction of disease index on faba bean germinated seeds set on fungal mycelial growth (2.3 \& 2.6 , respectively) compared with sodium nitrate (5.0). Otherwise, aspartic acid, phenylalanine and peptone showed nearly similar values of disease index as $\mathrm{NaNO}_{3}$ (Fig. 2).

Number of infection cushions for all treatments were counted $18 \mathrm{hr}$ after cotyledons were set on fungal growth, significant decrease of infection cushions was resulted when glucosamine sulfate, ammonium sulfate and peptone were used as sole source of nitrogen. According to statistical analysis, results were distinguished to four categories in descending order concerning No. of infection cushions: the first include only sodium nitrate, the second include aspartic acid and phenylalanine, the third include ammonium sulfate and peptone, and the last category included glucosamine sulfate (Fig. 3). On the other hand, glucosamine sulfate or ammonium sulfate led to significant reduction of hyphal diameter compared with sodium nitrate (Figs. 3 \& 4).

Effect of preparation of $\boldsymbol{R}$. solani inoculum on different nitrogen sources on its pathogenicity under greenhouse conditions

According to the obtained results in Fig. (5), different fungal inocula showed variant effects on disease index on faba bean roots. Inocula prepared on sodium nitrate, ammonium sulfate or phenylalanine gave the higher disease index values followed by aspartic acid and peptone, respectively. However, inoculum prepared on glucosamine sulfate led to the lowest disease index grade. Meanwhile, glucosamine sulfate showed promotion of seedling emergence and improvement of all plant growth characters (Fig. 6). Meanwhile, morphological features of root system were varied according to source of nitrogen applied. Ammonium sulfate, aspartic acid, sodium nitrate and phenylalanine showed very weak root in compared to root growth in non infested soil or that inoculated by fungal inoculum prepared on glucosamine sulfate (Fig. 7).

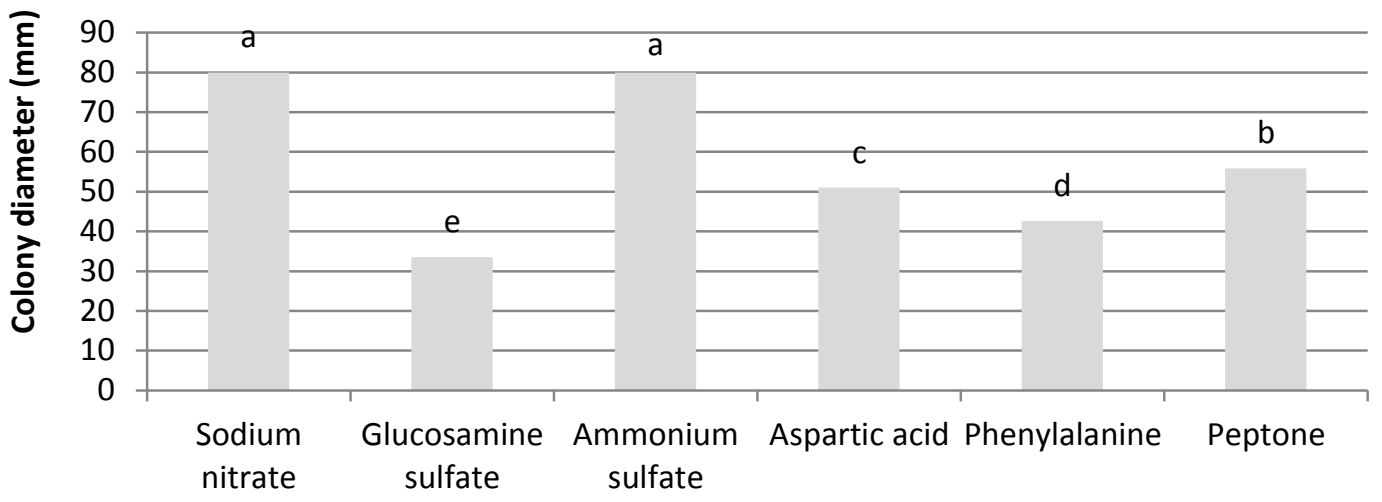

Nitrogen sources

Fig. 1. Effect of different nitrogen sources on colony radial growth of $R$. solani in vitro 72 hr after subculturing. Data were subjected to analysis of variance. The columns with the same letter are not significantly different. 


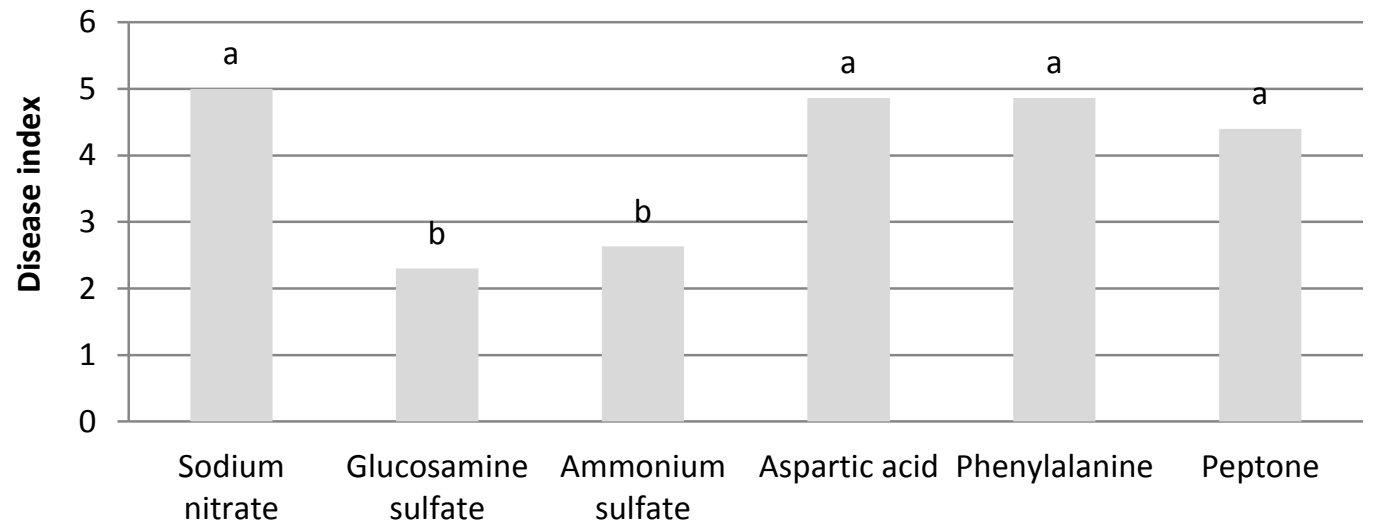

Nitrogen sources

Fig. 2. Effect of different nitrogen sources on disease index of $R$. solani on faba bean germinated seeds in vitro. Data were subjected to analysis of variance. The columns with the same letter are not significantly different

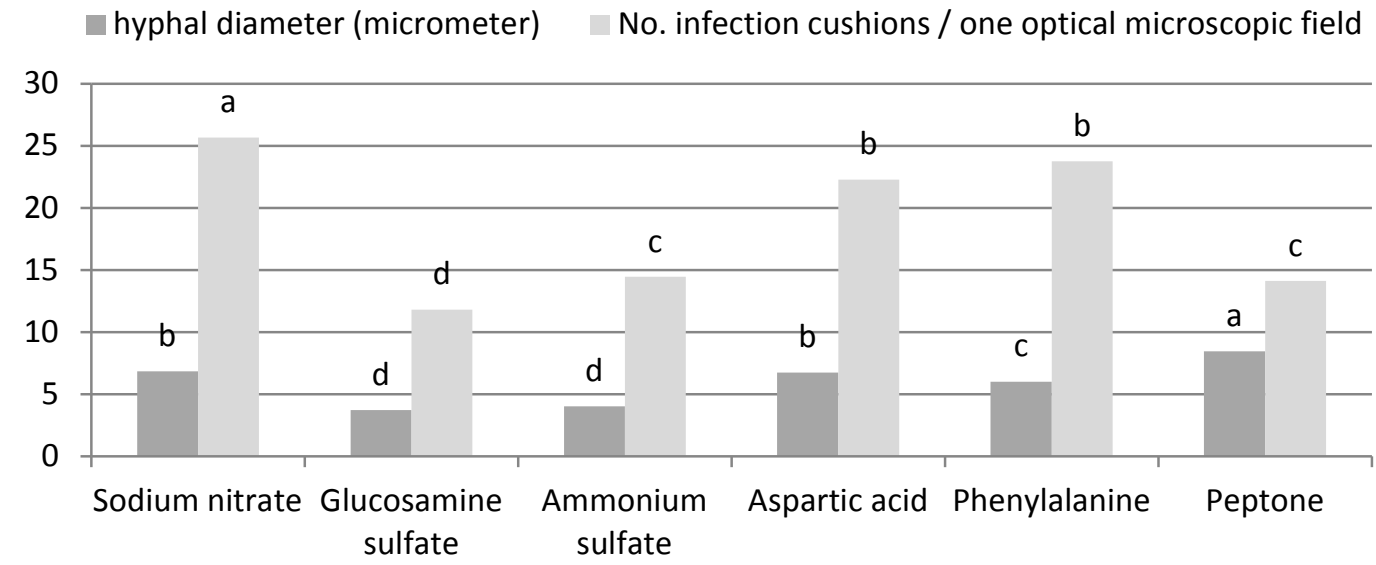

\section{Nitrogen sources}

Fig. 3. Effect of different nitrogen sources on mean number of infection cushions and hyphal diameter of $R$. solani formed on the lower surface of infected faba bean cotyledon $18 \mathrm{hr}$ after inoculation. Data were subjected to analysis of variance. The columns with the same letter are not significantly different 


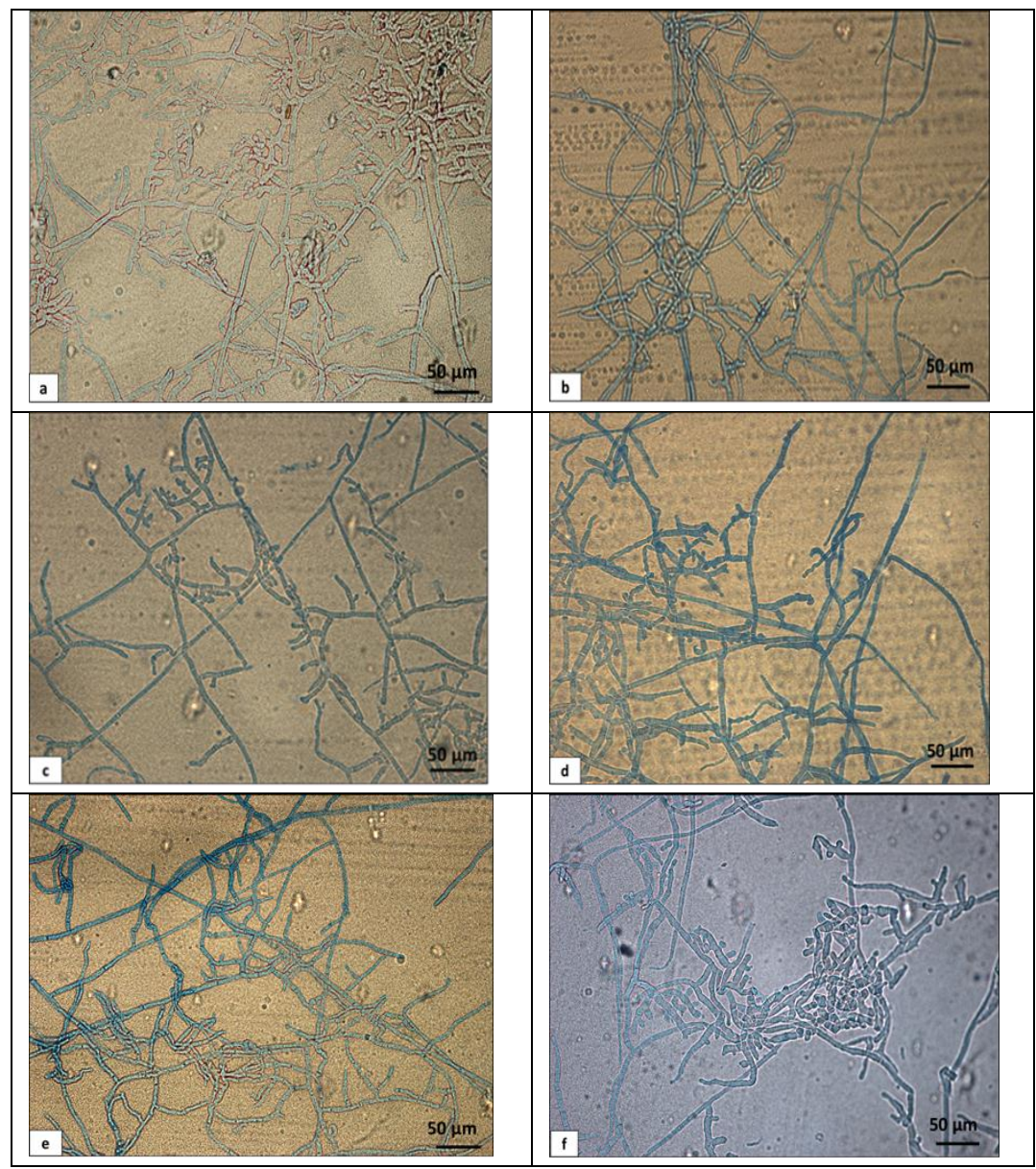

Fig. 4. Effect of different nitrogen sources in Czapek's medium on infection cushions and hyphal diameter of $R$. solani produced after $18 \mathrm{hr}$. on the lower surface of infected faba bean cotyledons. a: sodium nitrate, b:glucosamine sulfate, c: ammonium sulfate, d: aspartic acid, e: phenylalanine, f: peptone.

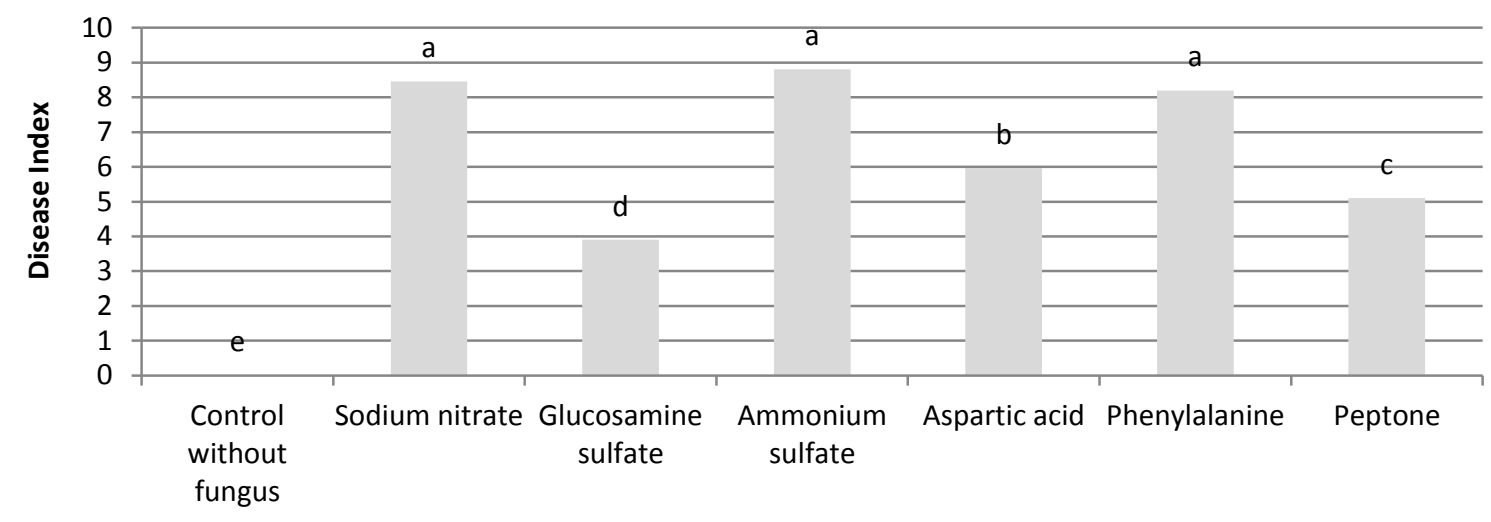

Nitrogen sources

Fig. 5. Effect of inoculum of $R$. solani on different nitrogen sources on root rot index of faba bean plants under greenhouse conditions. Data were subjected to analysis of variance. The columns with the same letter are not significantly different 


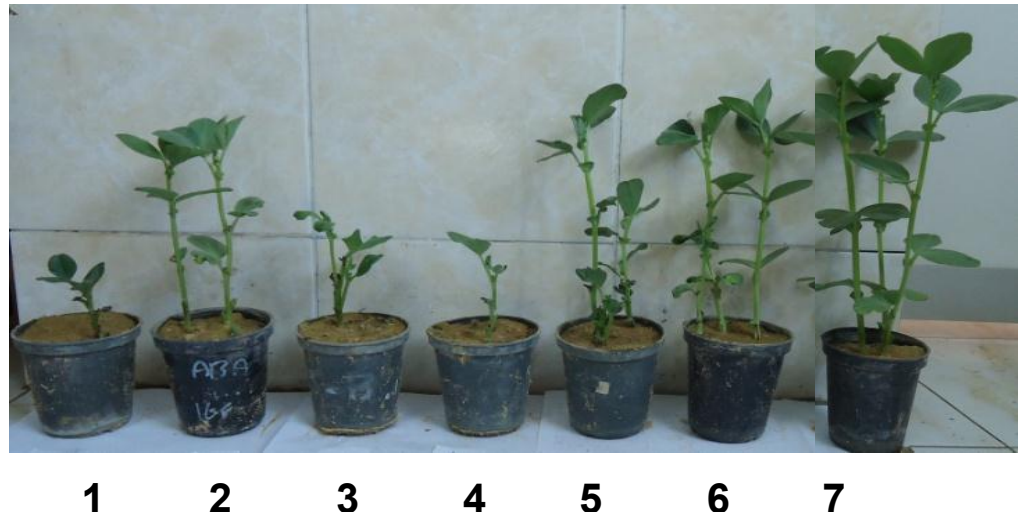

Fig. 6. Effect of inoculum of $R$. solani on different nitrogen sources on plant growth characters of faba bean plants. 1: sodium nitrate, 2: aspartic acid, 3: phenylalanine, 4: ammonium sulfate, 5: peptone, 6: glucosamine sulfate, 7: control without fungus. (Photographs illustrating; the great differences in plant growth at different treatments)

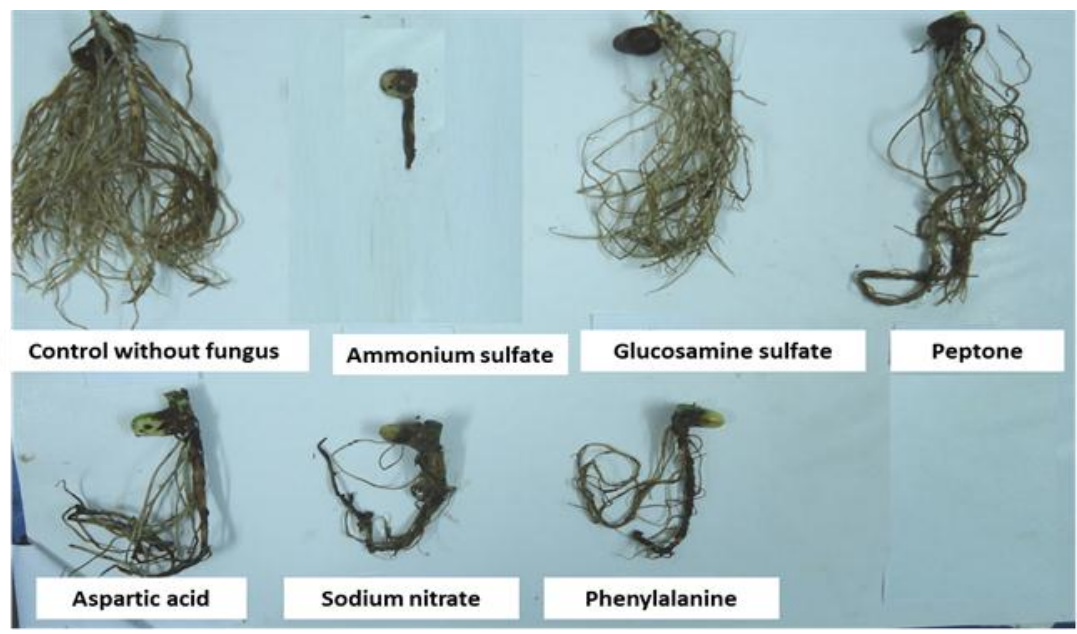

Fig. 7. Effect of inoculum of $R$. solani on different nitrogen sources on root morphology of faba bean root system

Effect of growing $\boldsymbol{R}$. solani on Czapek's medium amended with different amounts of glucosamine sulfate on fungal growth, morphology and it's pathogenicity on germinated faba bean seeds

Radial growth of $R$. solani on Czapek's medium amended with each of glucosamine sulfate three weights, was significantly reduced compared with control "medium with sodium nitrate". Such reduction was in maximal values with increasing glucosamine sulfate to double of normal weight (Fig. 8).
In laboratory, all different amounts of glucosamine sulfate depressed significantly disease index compared with sodium nitrate (Fig. 9). Significant fewer number of infection cushions was produced on the lower surface of cotyledons for all amounts of glucosamine sulfate (Fig. 10), compared with control.

Effect of different amounts of glucosamine sulfate on polyphenol oxidase (PPO) activity

Polyphenol oxidase activity in faba bean germinated seeds subjected to $R$. solani growth on different amounts of glucosamine sulfate showed 
significant decrease in enzymatic activity compared with sodium nitrate (Fig. 11).

Under greenhouse conditions, all amounts of glucosamine sulfate significantly decreased disease index (Fig. 12) and also showed significant increase on seedlings emergence $(92.5 \%)$ compared with $\mathrm{NaNO}_{3}$ treatment in infested sand. Meanwhile, glucosamine sulfate addition was ben- eficial for such seedling emergence near to healthy grown in uninfested soil (100\%). As well, similar effect was resulted for fresh weights of shoot and root compared with control plants treated with sodium nitrate (Table 1). Otherwise, no significant effect on both stem length and number of leaves/plant of all treatments (Table 1).

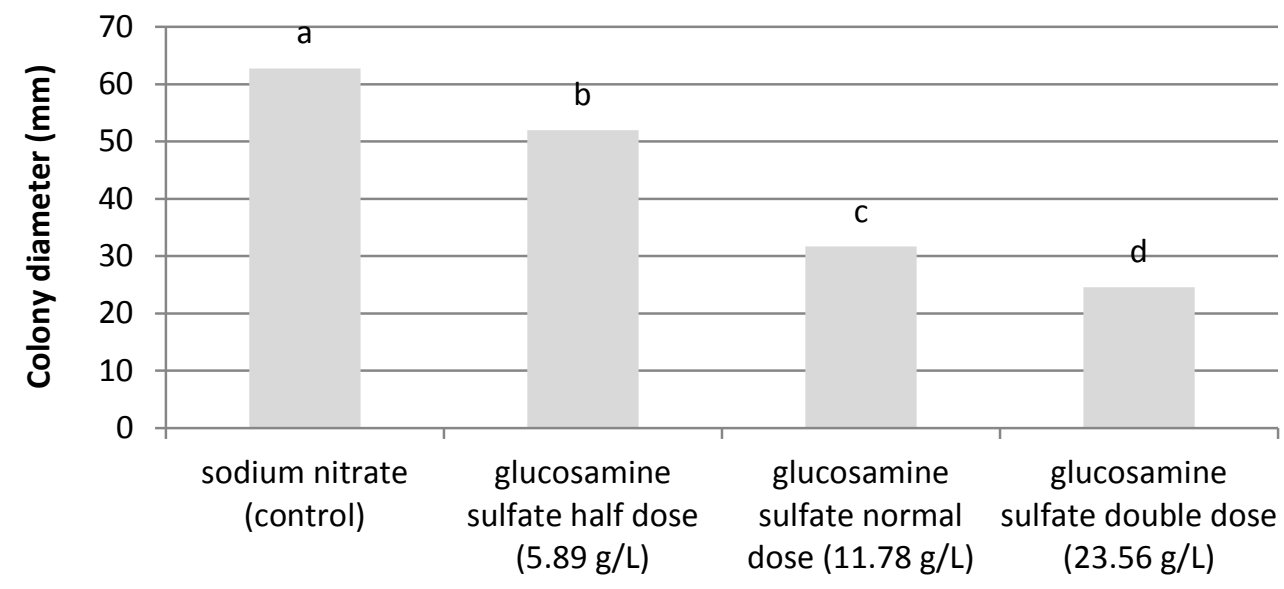

Nitrogen sources

Fig. 8. Effect of different amounts of glucosamine sulfate on radial growth of $R$. solani in vitro, $72 \mathrm{hr}$ after sub-culturing. Data were subjected to analysis of variance. The columns with the same letter are not significantly different

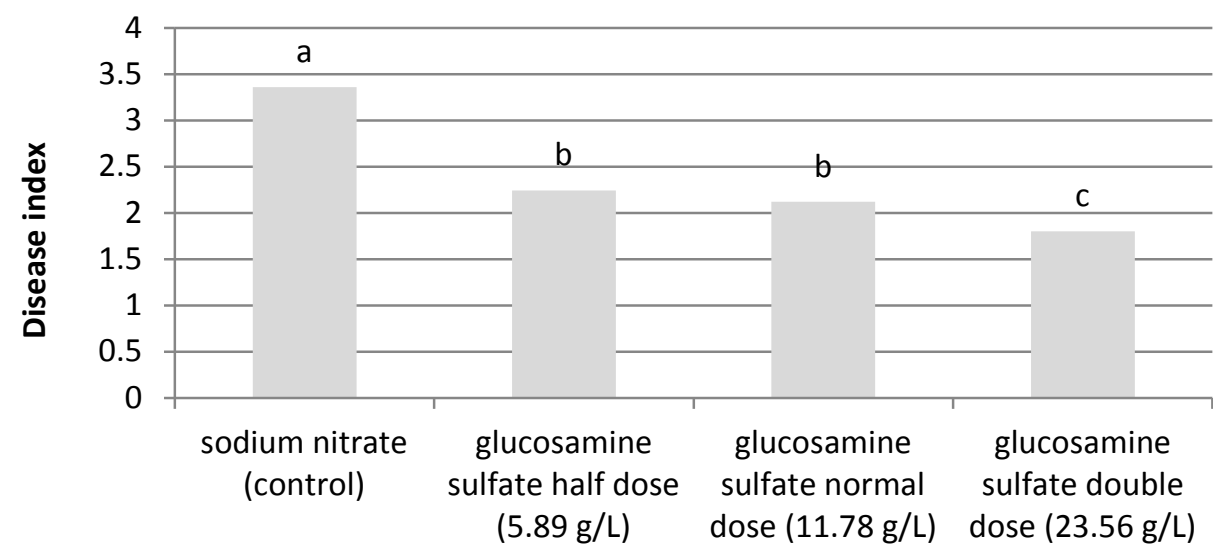

Nitrogen sources

Fig. 9. Effect of different amounts of glucosamine sulfate on disease index of $R$. solani, 3 days after inoculation in vitro. Data were subjected to analysis of variance. The columns with the same letter are not significantly different 


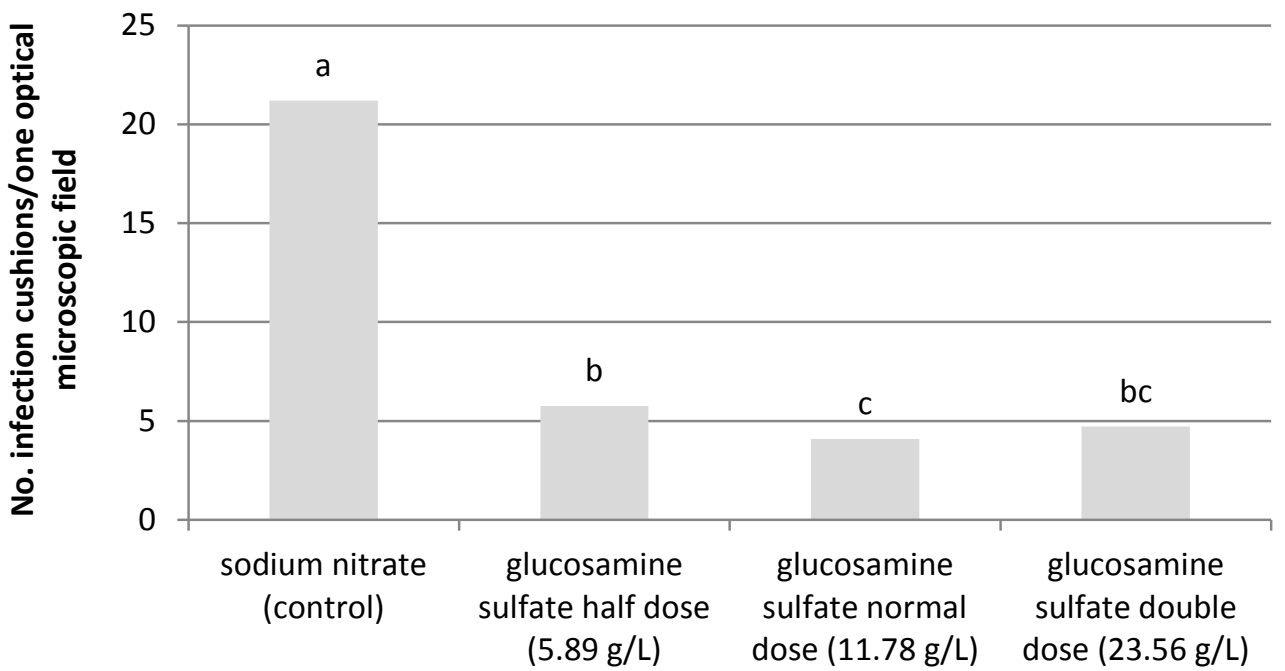

Nitrogen sources

Fig. 10. Effect of different amounts of glucosamine sulfate on mean number of infection cushions of $R$. solani produced on faba bean seeds, $18 \mathrm{hr}$ after inoculation. Data were subjected to analysis of variance. The columns with the same letter are not significantly different

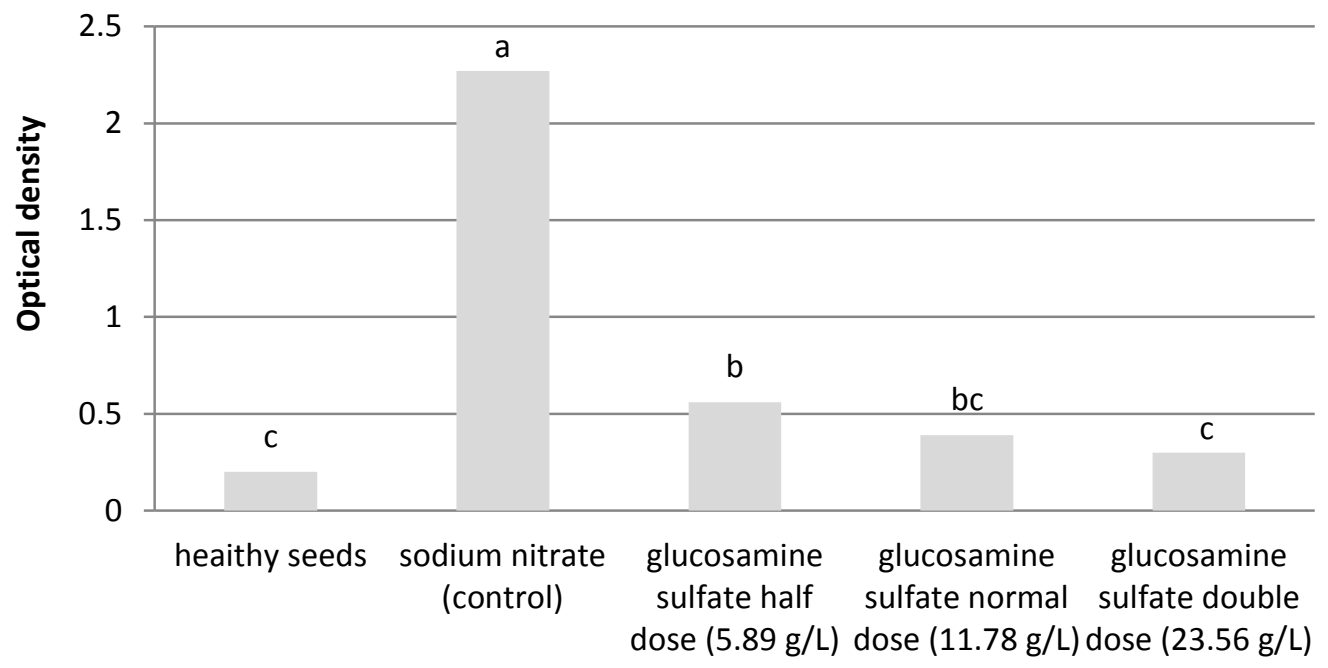

Nitrogen sources

Fig. 11. Polyphenol oxidase activity in faba bean germinated seeds subjected to $R$. solani growth on different amounts of glucosamine sulfate as a sole source of nitrogen. The optical density was recorded at after 15 minutes. Data were subjected to analysis of variance. The columns with the same letter are not significantly different 


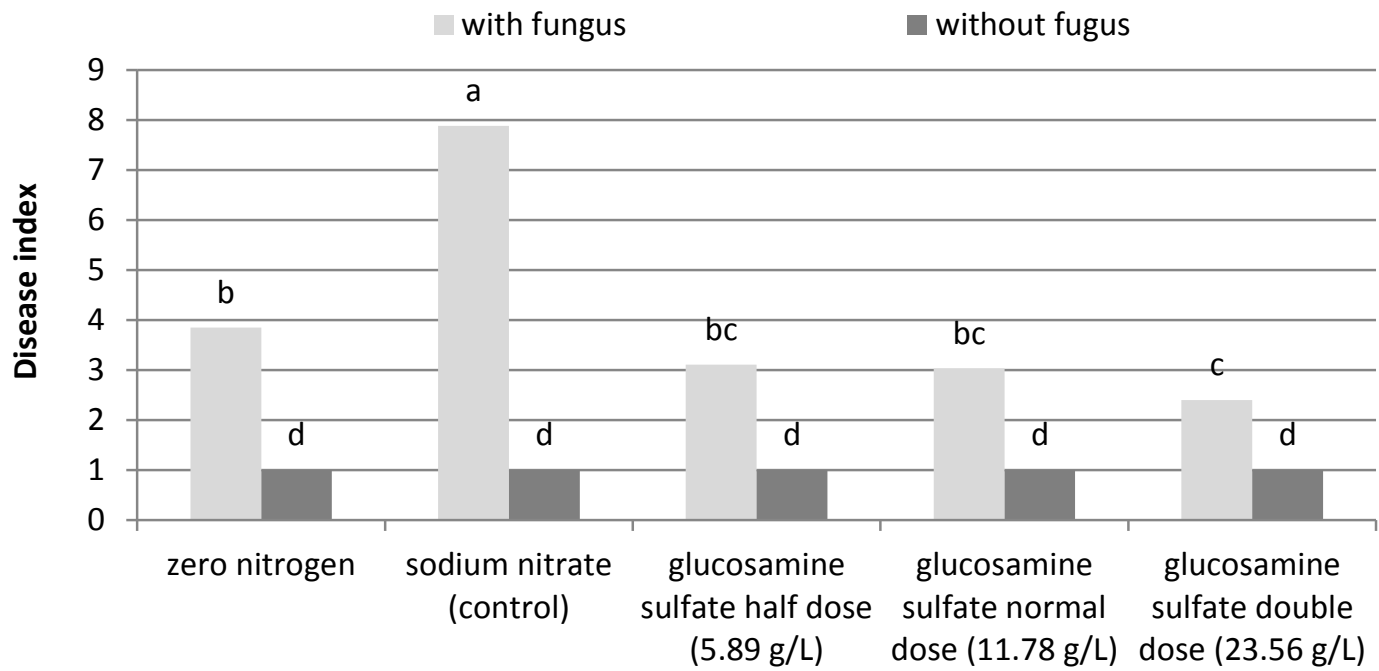

Nitrogen sources

Fig. 12. Effect of different amounts of glucosamine sulfate on disease index of $R$. solani on faba bean plants under greenhouse conditions, after 28 days of inoculation. Data were subjected to analysis of variance. The columns with the same letter are not significantly different

Table 1. Effect of different amounts of glucosamine sulfate on plant growth characters of faba bean

\begin{tabular}{|c|c|c|c|c|c|}
\hline Nitrogen Sources & $\begin{array}{c}\text { Stem length } \\
\mathbf{( c m})\end{array}$ & $\begin{array}{c}\text { Number of } \\
\text { leaves / } \\
\text { plant }\end{array}$ & $\begin{array}{c}\text { Fresh } \\
\text { shoot } \\
\text { weight } \\
\mathbf{( g )}\end{array}$ & $\begin{array}{c}\text { Fresh root } \\
\text { weight } \mathbf{( g )}\end{array}$ & $\begin{array}{c}\text { Percentage of } \\
\text { seedling } \\
\text { emergence } \\
(\%)\end{array}$ \\
\hline With fungus & & & & & \\
\hline Zero nitrogen & $29.6 \pm 4.6 \mathrm{bc}$ & $4.9 \pm 0.8 \mathrm{a}$ & $4.8 \pm 1.8 \mathrm{bc}$ & $4.8 \pm 0.6 \mathrm{~b}$ & $81.4 \pm 17.5 \mathrm{~b}$ \\
Sodium nitrate & $29.3 \pm 6.3 \mathrm{bc}$ & $4.8 \pm 1.3 \mathrm{a}$ & $2.7 \pm 09 \mathrm{~d}$ & $2.8 \pm 0.9 \mathrm{c}$ & $55.5 \pm 16.6 \mathrm{c}$ \\
Glucosamine sulfate half dose & $28.4 \pm 4.3 \mathrm{c}$ & $4.7 \pm 1.0 \mathrm{a}$ & $4.9 \pm 1.1 \mathrm{bc}$ & $6.9 \pm 2.2 \mathrm{a}$ & $92.5 \pm 14.7 \mathrm{ab}$ \\
Glucosamine sulfate normal dose & $29.4 \pm 4.1 \mathrm{bc}$ & $4.8 \pm 1.1 \mathrm{a}$ & $4.8 \pm 0.8 \mathrm{bc}$ & $7.2 \pm 1.8 \mathrm{a}$ & $92.5 \pm 14.7 \mathrm{ab}$ \\
Glucosamine sulfate double dose & $29.6 \pm 4.0 \mathrm{bc}$ & $4.8 \pm 0.7 \mathrm{a}$ & $5.9 \pm 1.8 \mathrm{a}$ & $7.1 \pm 2.0 \mathrm{a}$ & $92.5 \pm 14.7 \mathrm{ab}$ \\
\hline Without fungus & & & & & \\
\hline Zero nitrogen & $31.7 \pm 5.2 \mathrm{ab}$ & $4.8 \pm 0.9 \mathrm{a}$ & $5.4 \pm 1.6 \mathrm{ab}$ & $7.3 \pm 1.7 \mathrm{a}$ & $100.0 \pm 0.0 \mathrm{a}$ \\
Sodium nitrate & $32.2 \pm 5.3 \mathrm{ab}$ & $4.6 \pm 1.2 \mathrm{a}$ & $4.8 \pm 1.4 \mathrm{bc}$ & $7.3 \pm 1.9 \mathrm{a}$ & $100.0 \pm 0.0 \mathrm{a}$ \\
Glucosamine sulfate half dose & $33.8 \pm 5.5 \mathrm{a}$ & $4.9 \pm 0.7 \mathrm{a}$ & $4.3 \pm 1.4 \mathrm{c}$ & $7.4 \pm 1.7 \mathrm{a}$ & $100.0 \pm 0.0 \mathrm{a}$ \\
Glucosamine sulfate normal dose & $32.2 \pm 4.3 \mathrm{ab}$ & $4.6 \pm 0.5 \mathrm{a}$ & $4.2 \pm 1.0 \mathrm{c}$ & $7.0 \pm 1.9 \mathrm{a}$ & $100.0 \pm 0.0 \mathrm{a}$ \\
Glucosamine sulfate double dose & $34.7 \pm 4.7 \mathrm{a}$ & $5.0 \pm 0.5 \mathrm{a}$ & $5.3 \pm 1.1 \mathrm{ab}$ & $7.1 \pm 1.7 \mathrm{a}$ & $100.0 \pm 0.0 \mathrm{a}$ \\
\hline ANOVA $\boldsymbol{P}$ value & $<0.0001$ & $<0.0001$ & $<0.0001$ & $<0.0001$ & $<0.0001$ \\
\hline
\end{tabular}

Data were subjected to analysis of variance (ANOVA). Numbers within a column followed by the same letters are not significantly different. $( \pm)$ is a standard deviation. 


\section{DISCUSSION}

Nitrogen $(\mathrm{N})$ considers one of the most vital components in dietary of all prokaryotic and eukaryotic organisms. Source of such vital compound ranged from atmospheric $\mathrm{N}_{2}$ to mineral $\mathrm{N}$ as nitrites or nitrates amine or as ammonium salts. Organic compounds contain $\mathrm{N}$ as organic structure ranging from amino acids to polypeptides and proteins. Rhizoctonia solani can utilize all figures of $\mathrm{N}$ compounds except atmospheric N (Stephen and Fung, 1971). This fungus consider one of soil borne phytopathogenic fungi, it does distribute in all cultivated soil causing very serious plant diseases include damping-off, root rot, stem canker and can cause death of plants (Trivedi et al 2017). Since cultivated soil usually fertilized by different $\mathrm{N}$ sources includes nitrate, ammonium salts or organic amendments, then the fungal inoculum will feed either of these fertilizers which may affect its pathogenicity. The fungus usually survives in soil as sclerotia which germinate in the presence of suitable host to infect it. The fungus needs many nutrients for both germination and growth of sclerotia (Moromizato et al 1980 and Ritchie et al 2009).

The present study was passed through different ascending steps. The first one is studying the effect of nitrogen sources included mineral, i.e. sodium nitrate, ammonium sulfate or simple organic, i.e. glucosamine sulfate, phenylalanine, aspartic acid and protein, i.e. peptone on fungal growth and its pathogenicity on faba bean germinated seeds. The second one includes preparation of fungal inoculum on different mentioned sources in order to study their effect on fungal pathogenicity on faba bean plants. The third, is selection the best nitrogen source that reduced the efficacy of the pathogen to infect faba bean plant was chosen for further study.

Concerning the first step, ammonium sulfate stimulated fungal growth, however, glucosamine sulfate showed the lowest growth. The efficacy of such growth on disease index on faba bean germinated seeds indicated that growth of fungus on glucosamine sulfate has significantly reduced its pathogenicity. Does such reduction was occurred due to fail of growth mats grown on glucosamine sulfate to produce its infection cushions? From data obtained in the present study, number of infection cushions on faba bean cotyledons was significantly lowered with glucosamine sulfate. Infection cushions of $R$. solani are the first process of successful parasitism and their reduction will re- flect on disease severity (Murray, 1982 and Kim et al 2001).

Results of this study showed high positive correlations between disease index and both of diameter of fungal hyphae and number of infection cushions for all treatments $(+0.82 \&+0.84$, respectively). However, very weak correlation coefficient between disease index and growth of $R$. solani is recorded $(+0.11)$.

Concerning the second step, fungal inoculum was prepared on different nitrogen sources, data obtained showed that preparation of fungal inoculum on Czapek's medium contained glucosamine sulfate instead of sodium nitrate led to a significant reduction of disease index in comparison with other nitrogen sources. Does glucosamine sulfate can down regulate pathogenicity genes of $R$. solani? This point needs further study.

In the third step, glucosamine sulfate when applied in three concentrations i.e., half, normal, and double dose on fungal growth and its morphology, pathogenicity of fungal mats on faba bean germinated seeds, infection cushions and on polyphenol oxidase activity in infected seeds. Data obtained indicated that by increasing glucosamine sulfate concentration in fungal medium growth was proportionally retained to increase the tested criteria. It was noticed that presence of glucosamine sulfate in fungal growth medium led to complete failure in producing sclerotia. In this respect, Moromizato et al (1980) have found that some sulfur containing amino acids inhibit sclerotial formation of $R$. solani. Number of infection cushions was found to be less than that found on the normal medium with $\mathrm{NaNO}_{3}$. However, ammonium sulfate as sole source of nitrogen increased both fungal growth, and sclerotial formation. Meanwhile, as mentioned before, amino acids containing sulfur inhibit sclerotia but according results obtained now study this effect may not due to sulfur alone, since the fungus $R$. solani produced sclerotia well on ammonium sulfate. This phenomenon was reflected on disease index where, it decreased by increasing glucosamine sulfate concentrations although, the seeds were directly set on fungal mats. Decreasing of disease index may be due to the reduction of infection cushions number which was obviously observed in this study. In order to insure that glucosamine sulfate affect the fungal pathogenicity, polyphenol oxidase activity (PPO) was determined in faba bean seeds subjected the fungal growth hence it was found that the activity of PPO increase by increasing disease severity (Shetty et al 
2001 and Parihar et al 2012). These results greatly indicate that glucosamine sulfate can affect the process of invasion during pathogenesis of such fungus due to retarding of pathogenicity gene (Lakshman et al 2012).

The last step in this investigation included the treatment of infested sand by different concentrations of glucosamine sulfate then, were sown germinated faba bean seeds in such sand soil. Sand was used for seeding faba bean seeds instead of natural soil to prevent any interference between glucosamine sulfate and other naturally found $\mathrm{N}$ sources in natural soil.

In addition, data obtained indicated that glucosamine sulfate proved its efficacy on disease index which was obviously reduced by increasing glucosamine sulfate concentration. Such beneficial effect was also reflected on plant growth parameters i.e. seedling emergence, stem length, number of leaves/plant, and fresh weights of shoot and root. As a conclusion, glucosamine sulfate reduced $R$. solani growth, completely inhibited sclerotial production by the fungus, reduced disease index, and increased parameters of plant growth. Our study proposes that glucosamine sulfate may acts as controlling factor of pathogenicity genes of $R$. solani.

\section{REFERENCES}

Duvenhage J.A., Kotze, J.M. and Maas E.M.C. 1992. The influence of nitrogen and calcium on mycelial growth and disease severity of Phytophthora cinnamomi and the effect of calcium on resistance of avocado to root rot. South African Avocado Growers Association Yearbook, 15, 12-14.

Ghahramani S. 2000. Fundamentals of probability $\left(2^{\text {nd }}\right.$ Ed.). Prentice Hall: New Jersey, USA, 438 p.

Huber D.M. and Watson R.D. 1974. Nitrogen form and plant disease. Annu. Rev. Phytopathol., 12,139-165.

Islam R. 2015. Effect of various carbon and nitrogen sources on mycelial growth of Fusarium spp. isolated from agricultural fields of Murshidabad. Ind. J. Sci. Res. and Tech., 3(1), 71-77.

Jabin F. and Nasreen S. 2016. Effect of nitrogen sources on growth and sporulation of Alternaria solani. Int. J. Sci. Res., 5(2), 343-346.
Kim H.T., Chung Y.R. and Cho K.Y. 2001. Mycelial melanization of Rhizoctonia solani AG1 affecting pathogenicity in rice. Plant Pathol. J., 17(4), 210-215.

Lakshman D.K., Alkharouf N., Roberts D.P., Natarajan S.S. and Mitra A. 2012. Gene expression profiling of the plant pathogenic basidiomycetous fungus Rhizoctonia solani AG 4 reveals putative virulence factors. Mycologia, 104(5), 1020-1035.

Littell R.C., Milliken G.A., Stroup W.W., Wolfinger R.D. and Cary N.C. 1996. SAS system for mixed models. SAS Institute Inc., 633 p.

Marzluf G.A. 1997. Genetic regulation of nitrogen metabolism in the fungi. Microbiol. Mol. Biol. Rev., 61, 17-32.

Mohamed M.H., Gado E.A.M., El-Deeb S.H. and Mostafa M.H. 2014. Effect of nitrate levels as a fertilizer or as a fungal nutrition on the aggressiveness of Rhizoctonia solani on faba bean. European J. Advanced Research in Biological and Life Sci., 2(2), 1-13.

Mohamed M.H., Gado E.A.M., El-Deeb S.H. and Mostafa M.H. 2015a. Obstruction of signal transduction between faba bean and Rhizoctonia solani during pathogenesis and its impact on root rot disease. Int. Sci. Res. J., 1, 99-107.

Mohamed M.H., Gado E.A.M., El-Deeb S.H. and Mostafa M.H. 2015b. Phenotypic diversity and molecular identification of the most prevalent anastomosis group of Rhizoctonia solani isolated from diseased faba bean plants. American J. Life Sci., 3(1), 47-55.

Moromizato Z., Matsuyama N. and Wakimoto S. 1980. The effect of amino acids on sclerotium formation of Rhizoctonia solani Kühn (AG-1) I. Inhibition of sclerotial formation by various amino acids. Ann. Phytopath. Soc. Japan., 46, 15-20.

Murray D.I.L. 1982. Penetration of barley root and coleoptile surfaces by Rhizoctonia solani. Trans. Br. Mycol. Soc., 79(2), 354-361.

Parihar P.S., Prakash O. and Punetha H. 2012. Investigation on defensive enzymes activity of Brassica juncea genotypes during pathogenesis of Alternaria blight. Nature and Sci., 10(2), 63-68.

Ritchie F., Bain R.A. and McQuilken M.P. 2009. Effects of nutrient status, temperature and $\mathrm{pH}$ on mycelial growth, sclerotial production and germination of Rhizoctonia solani from patato. J. Plant Pathol., 91(3), 589-596. 


\section{Influence of Different Nitrogen Sources on Growth and Pathogenic

Shetty H.S., Vasanthi N.S., Sarosh B.R. and Kini K.R. 2001. Inheritance of downy mildew resistance, $\beta$-1,3-glucanases and peroxidases in pearl millet [Pennisetum glaucum (L.) R. Br.] crosses. Theor. Appl. Genet., 102(8), 12211226.

Stephen R.C. and Fung K.K. 1971. Nitrogen requirements of the fungal endophytes of Arundina chinensis. Nitrogen requirements of the fungal endophytes of Arrinrlilln chinensis. Can. J. Bot., 49, 407-410.
Trivedi A., Sharma S.K., Chaudhary R., Jajoria D.K., Jain R.K. and Yadav S.K. 2017. Management of dry root rot caused by Rhizoctonia solani in organic Gram. Int. J. Curr. Microbiol. App. Sci., 6(8), 3647-3652.

Ünal M.Ü. 2007. Properties of polyphenol oxidase from Anamur banana (Musa cavendishii). Food Chemistry, 100, 909-913.

White C. and Gadd G.M. 1983. Effect of glucosamine on morphology of Verticillium albo-atrum. Trans. Br. Mycol. Soc., 80(3), 533-536. 




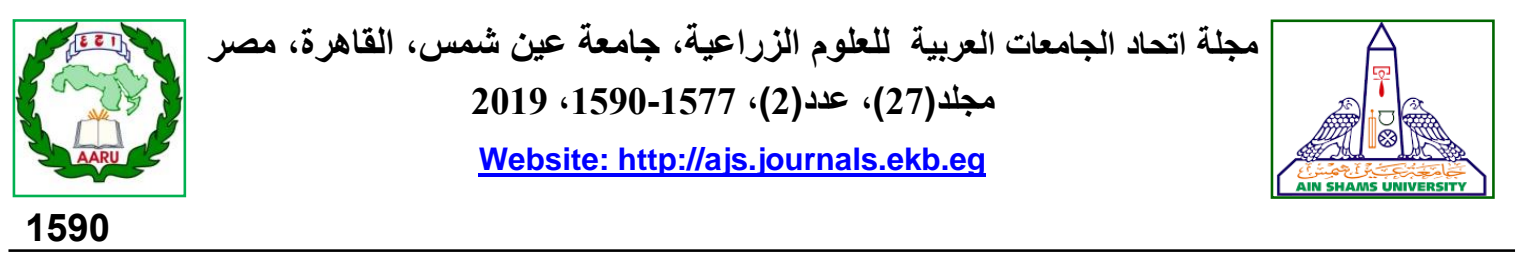

Rhizoctonia solani تأثير اختلاف مصادر النيتروجين على النمو والقدرة المرضية لفطر المسبب لعفن الجذور في الفول ولمول

\author{
مها حلمي محمد" - مصطفى حلمي مصطفى \\ قسم أمراض النبات - كلية الزراعة - جامعة عين شمس - ص.ب 68 - 11241 حدائق شبرا - القاهرة - مصر
}

*Corresponding author: maha helmy83@agr.asu.edu.eg

Received 19 October, 2018

Accepted 7 December, 2018

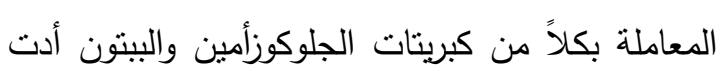

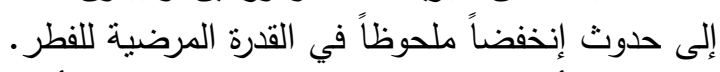

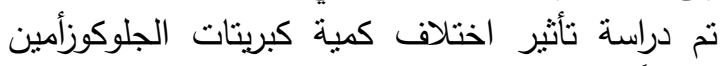

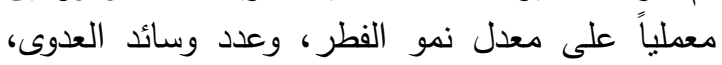

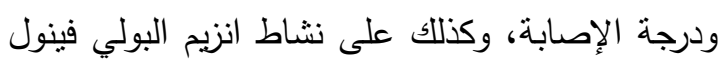

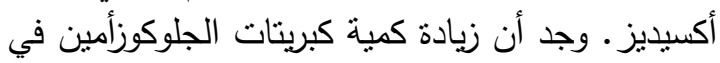

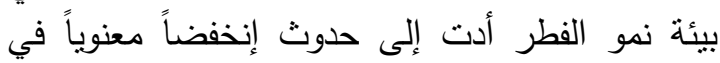

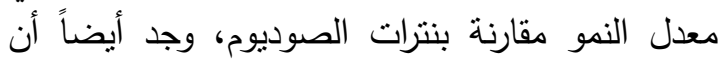

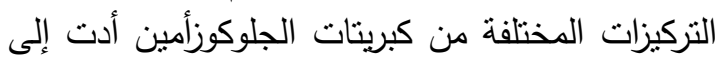

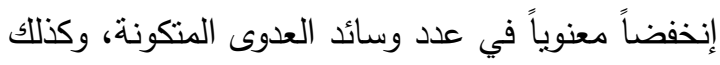

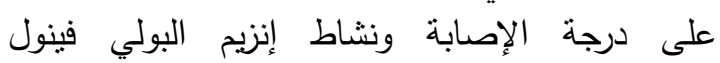

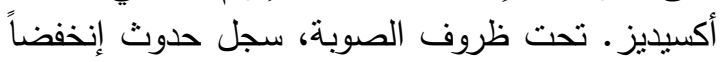

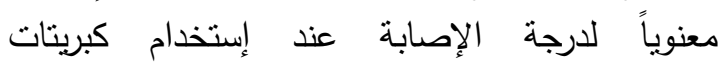

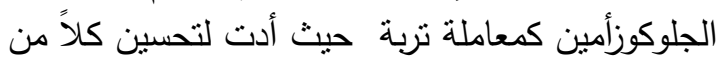

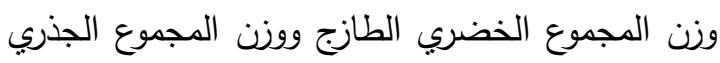

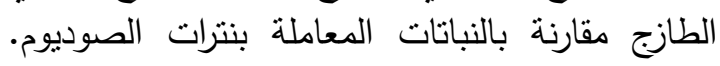

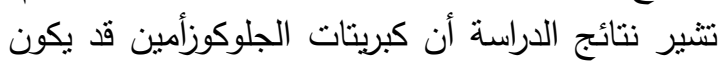

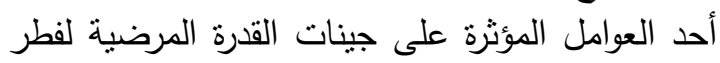
. R. solani

الكلمات الدالة: Rhizoctonia solani ، الفات ، الفول، Vicia faba امين، القدرة المرضية

\section{الموجـــــــز}

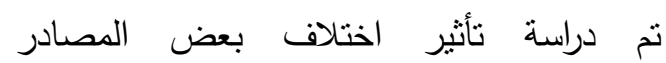

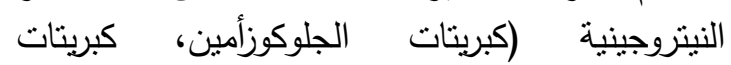
الأمونيوم، حمض الأسبارتك، الفينيل الانين، والبيتون)

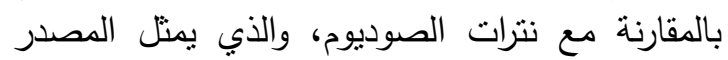

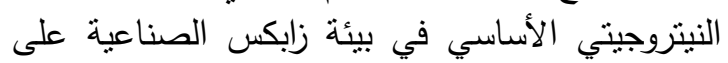

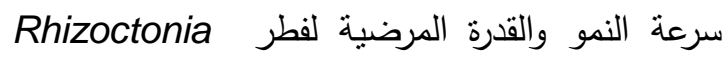
solani

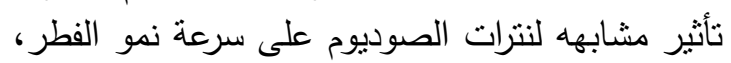

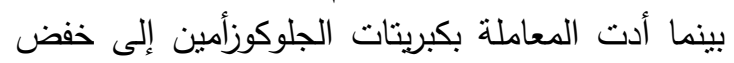

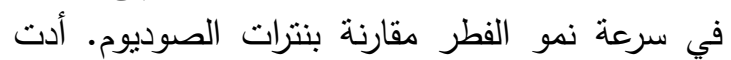

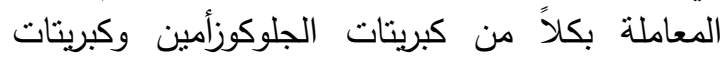

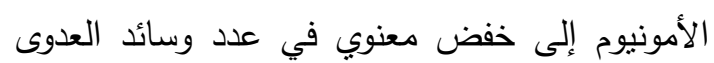

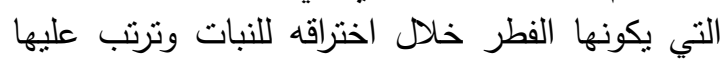
كذللك إنخفضاً معنوياً في درجة الإصابة التهابة معملياً.

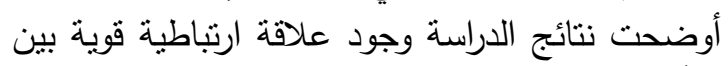

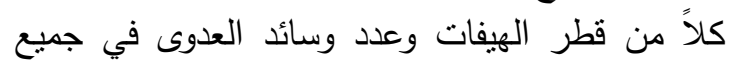
المعاملات ، بينما وجد علاقة ارتباطية ضعيفة وعند بين كلاً

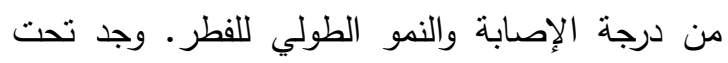
ظروف الصوبة عند استخدام المصادر النيتروجينة ولنية كمصدر وحيد للنيتروجين في بيئة نمو الفطر أن الن 